\title{
Ameliorative Effect of Flavonoid Antioxidant on the Histology and Ultrastructure of Albino Rats` Liver Treated with Radiation and /or Acrylonitrile
}

\author{
M. A. Ashry ${ }^{1}$, A.M. Farg alla ${ }^{1}$, M. G. AbdElazeem ${ }^{2}$, M. \\ M. Samy ${ }^{2}$ \\ 1 Zoology Dept., Girls`College, Ain Shams University. \\ 2 National Center for Radiation Research and Technology. (NCRRT)
}

\begin{abstract}
The present study was established to investigate the effect of acrylonitrile toxicity or/and $\gamma$-irradiation on albino rats liver tissue and the role of hesperidin in recovery and improvement. eighty male albino rats (100-110gm) were divided into eight groups. Control group received orally a mixture of dimethyl sulphoxide and water (1: 9, v/v); Acrylonitrile treated group was given daily dose of $(50 \mathrm{mg} / \mathrm{kg}$ body weight)/day for 4 weeks; Acrylonitrile or/and group exposed to whole body $\gamma$-irradiation up to dose of $6 \mathrm{~Gy}$ accumulative dose; Hesperidin treated group received daily dose of (100 mg/kg body weight) for 4 weeks; hesperidin and acrylonitrile daily dose of $(50 \mathrm{mg} / \mathrm{kg}$ body weight)/day and/or $\gamma$-irradiation up to dose of $6 \mathrm{~Gy}$ accumulative dose $(1.5 \mathrm{~Gy} /$ week). Light and transmissionelectron microscopic were used to examine liver tissue. The histological investigation showed deterioration in the liver's tissues pattern in the acrylonitrile treated group or/and $\gamma$-irradiated one. The results obtained, showed an improvement in liver tissue in the groups treated with hesperidin. Such results indicated that co-administration of hesperidin was found to be more effective in restoring, histological and electron microscopic alterations.
\end{abstract}

Keywords:Radiation, Acrylonitrile, Hesperidin, Liver.

\section{Introduction}

The development of a technological society is associated with increasing environmental pollution and reduced immunity to disease. Radiation, oxidation and toxic substances are all potentially damaging factors. Radiation is one of the most important environmental factors because of its hazardous health effects (Mothersill and Seymour, 2005). Ionizing radiation is known to induce oxidative stress through generation of reactive oxygen species (Lin $\boldsymbol{e t}$ al., 2011). Those reactive oxygen species (ROS)results in imbalance of the pro-oxidant and antioxidant in the cells attack diverse cellular macromolecules such as DNA, lipids, and proteins and eventually inducing cell death (Kanimozhi et al., 2011). Lipid peroxidation (LPO) is one of the major forms of cellular damage induced by radiation (Kamat et al., 2000). Lipid peroxidation (LPO) is oxidative deterioration of polyunsaturated lipids.Histological examination of liver sections of $\gamma$-irradiated rats resulted in many pathological criteria (Kátia, 2012).

Acrylonitrile (ACN), an organic nitrile, is widely used in the manufacturing of fibers, plastics and pharmaceuticals (Haber and Patterson, 2005). Acrylonitrile has two chemically active sites, at the carbon-carbon double bond and at the nitrile group, where it undergoes a wide variety of reactions. (El-Sayed et al., 2008). The metabolism of Acrylonitrile (ACN) resulted in the production of cyanide, where cyanide has beenreported to induce oxidative stress and lipid peroxidation. (Rongzhu et al., 2009). The major pathway of ACN elimination is its conjugation with glutathione (GSH), the process results in a rapid depletion of cellular antioxidant contents

Corresponding Author: marwasamy1210@gmail.com 
(Abo-Salem et al., 2011).

Liver was used in this study because it has been reported as a highly radiosensitive organ (Kunticet al., 2014). Hepatic injury can be life threatening when the entirely or most of the liver is exposed to ionizing radiation. Also, it is the primary organ responsible for drug metabolism and mainly detoxifies damaging electrophiles generated during oxidative stress. This tissue is rich in endogenous antioxidants and related enzymes (Eidet al., 2015).

Since time immemorial, the plant kingdom has exhibited adverse array of biological activities. Several plant products have also been employed for mitigating the ionizing radiationinduced damage in mammalian systems (Paul $\boldsymbol{e t}$ al., 2011). This is owing to the polyphenolic constitution of plant material, among which flavonoids are most abundant and responsible in attenuating the radiation-induced oxidative distress (Benkovic et al., 2008;Kalpanaet al., 2011).

Hesperidin, a flavanone-type flavonoid, is found abundant in citrus fruit (Seyed $\boldsymbol{e t}$ al. 2003). Hesperidin has been reported to exert a wide range of pharmacological effects (Tommasini et al., 2005).It includes antioxidant, anti-inflammatory, anti-allergic, hypolipidemic, vaso-protective and anti-carcinogenic actions (Kalpanaet al., 2011). Oral administration of hesperidin revealed that most of the hepatocytes became within normal limits due to its free radical scavenging properties and antioxidant nature preserving the integrity of tissue (Kunticet al., 2014). The aim of the present work is to investigate the role of hesperidin in reducing the deleterious effect of ACN and gamma radiation on rat liver.

\section{Materials and Methods}

\subsection{Chemicals:}

Acrylonitrile $>99 \%$, contains $35-45 \mathrm{ppm}$ monomethyl ether hydroquinone as inhibitor. Hesperidin Lot\# 011M1865V $\{>80 \%\}$. As well as other chemicals and solvents used in this study were of highest purity and analytical grade. The materials were purchased from SigmaAldrich chemical Co.USA.

\subsection{Gamma Irradiation}

Whole body $\gamma$-irradiation was performed usingCesium 137 Biological $\gamma$-cell-40 irradiation facility belonging to The National Center for Radiation Research and Technology (NCRRT).

\subsection{Animals and Experimental Design}

Eighty male albino rats weighing about 100-110 g were obtained from Animal House of Egyptian Organization for Vaccine and Biological Preparations at Helwan, Egypt. All animals were housed in plastic cages and kept under the same laboratory conditions of temperature $\left(25 \pm 2^{\circ} \mathrm{C}\right)$ and lighting $(12: 12 \mathrm{hr}$ light: dark cycle) for one week prior to starting the experiments. The rats were provided ad libitum with tap water and fed with standard laboratory diet. All animals received humane care in compliance with the international guiding principles for animal research. The dose of acrylonitrile was determined according to Rongzhu et al. (2009) to be 50 $\mathrm{mg} / \mathrm{kg}$ body weight oral administrated. Hesperidin was dissolved in a mixture of dimethylsulphoxide and water (1: $9, \mathrm{v} / \mathrm{v})$. at a dose of $100 \mathrm{mg} / \mathrm{kg}$ body weight oral administration. The dose of hesperidin used was determined according to Tirkey $\boldsymbol{e t}$ al. (2005) Animals were randomly divided into 8 groups of 10 animals each: 
Group I: Control group received orally a mixture of dimethyl sulphoxide and water (1: 9, v/v).

Group II: Rats received acrylonitrile orally in a daily dose of $50 \mathrm{mg} / \mathrm{kg} \mathrm{b}$. w. for 4 weeks.

Group III: Rats exposed to $\gamma$ radiation accumulative dose up to $6 \mathrm{~Gy}(1.5 \mathrm{~Gy} /$ week $\times 4)$.

Group IV: Rats received hesperidin orally in a daily dose of $100 \mathrm{mg} / \mathrm{kg} \mathrm{b}$. w. for 4 weeks.

Group V: Rats received acrylonitrile orally in a daily dose of $50 \mathrm{mg} / \mathrm{kg} \mathrm{b}$. w. for 4 weeks and exposed to $\gamma$ radiation accumulative dose up to $6 \mathrm{~Gy}(1.5 \mathrm{~Gy} / \mathrm{week})$.

Group VI: Rats received acrylonitrile orally in a daily dose of $50 \mathrm{mg} / \mathrm{kg} \mathrm{b}$. w. and hesperidin of $100 \mathrm{mg} / \mathrm{kg} \mathrm{b}$. w. for 4 weeks.

Group VII: Rats exposed to $\gamma$ radiation accumulative dose up to $6 \mathrm{~Gy}(1.5 \mathrm{~Gy} / \mathrm{week})$ and received hesperidin orally in a daily dose of $100 \mathrm{mg} / \mathrm{kg} \mathrm{b}$. w. for 4 weeks.

Group VIII: Rats exposed to $\gamma$ radiation accumulative dose up to $6 \mathrm{~Gy}$ (1.5 Gy/week) and received acrylonitrile orally in a daily dose of $50 \mathrm{mg} / \mathrm{kg} \mathrm{b}$. w. and hesperidin of $100 \mathrm{mg} / \mathrm{kg} \mathrm{b}$. w. for 4 weeks.

At the end of the experiment, all rats were sacrificed by decapitation under mild anesthesia (anesthetic ether) and the midline abdominal incision was done to get the liver. The right lobes were dissected and processed for light and transmission electron microscope examination.

\subsection{Histological study:}

For light microscope, the specimens were fixed in formal saline for 12 hours to prepare paraffin blocks. Sections $(5 \mu \mathrm{m})$ were prepared and stained by H\&E stain (Harris's, 1900). For transmission electron microscope, the specimens were immediately fixed in $2.5 \%$ gluteraldehde in cacodylate buffer at $\mathrm{pH} 7.4$ for 24 hours at $4^{\circ} \mathrm{C}$. Then the specimens were washed with the buffer and post fixed in $1 \%$ osmium tetroxide in distilled water for 2 hours at $4^{\circ} \mathrm{C}$. Specimens were dehydrated with ascending grades of ethanol and then put in propylene oxide to prepare Epon-Araldite resin blocks (Weakley, 1981). Ultrathin sections (70-90 nm) were obtained, stained by uranyl acetate and lead citrate and examined under JEOL 1010 electron microscope

\section{Results and Discussion}

\subsection{Results}

\subsubsection{Histological examination:}

Light microscope examination of the liver sections of control (group I) showed that the liver lobules consisted of anastomosing cords of hepatocytes radiating from central vein. The hepatocytes were acidophilic and contained central pale stained nuclei and some were binucleated.The hepatocyte cords were separated by narrow blood sinusoids lined with two types of cells, endothelial and kupffer cells. (Fig. A1)

Examination of the liver sections exposed to 6Gy $\gamma$-radiation (group II) evidenced dilatation of central veins and blood sinusoidal spaces,somehaemorrhagic areas. Kupffer cells become more active with prominent presence along the borders of sinusoidal spaces. Karyorrhexis and karyolysis of the nucleus were seen. Fibrous tissues appeared around central vein. Inflammatory infiltrative cells between the hepatocytes within patches of necrotic areas were obvious. Large areas of hepatocytes appeared with dark pyknotic nuclei.(Fig. A2)

The liver sections of acrylonitrile treated (group III) revealed dilatation and congestion of central vein. Fibrous tissues in the portal area and around the central vein were recognized with 
appearance of inflammatory infiltrative cells. Karyorrhexied, karyolytic and pyknotic nuclei were observed. Obvious dilatation in blood sinusoids and invasion of active kupffer cells were noticed.(Fig. A3)

Also the liver sections exposed to $\gamma$ irradiation and treated with acrylonitrile (group IV) showed focal or spotty necrosis throughout the lobule. Kupffer cells became more active with prominent presence along the borders of the sinusoidal spaces. Inflammatory response were also detected. Moreover, dark pyknotic, karyolytic and karyorrhexied nuclei were recognized.(Fig.A4)

Examination of the liver sections of hesperidin treated (groupV) manifested near to normal hepatic lobule in which the hepatocytes were arranged in cords radiating from the central veins to the periphery of the lobule.(Fig. A5)

The liver sections exposed to $\gamma$ irradiation and receiving hesperidin (group VI) revealed preserved structure of the hepatic tissue except the presence of hepatocytes with darkly stained nuclei.(Fig. A6)

Also the liver sections receiving acrylonitrile and hesperidin (group VII) authenticated ameliorated hepatic profiles with near to normal hepatic architecture.(Fig. A7)

Finally the liver sections treated with hesperidin and receiving acrylonitrile concomitantly with $\gamma$ radiation (group VIII), revealed preserved structure of hepatic tissue.(Fig. A8)

\subsubsection{Ultra-structural examination:}

Ultra-structural examination of the liver sections of control (groupI) showed hepatocytes contained euchromatic nuclei, mitochondria and rough endoplasmic reticulum. Bile canaliculiare formed by the plasma membranes of adjacent hepatocytes and tightly bounded by junctional complexes. Short microvilli were projecting into the bile canaliculi.(Fig. B9)

Ultra-structural examination of the liver sections exposed to $\gamma$ radiation (group II) revealed swollen fused mitochondria with ill-differentiated cristae, proliferation of smooth endoplasmic reticulum, vesiculation and fragmentation of the rough endoplasmic reticulum. Also, nuclear lesions were observed as ill-defined electron translucent nuclei with irregular outer boundary.(Fig. B10)

The liver exposed to acrylonitrile (group III) revealed abundant swollen with ill-defined cristae mitochondria some are fused and electron dense. Also abundant ruptured rough endoplasmic reticulum,binucleated hepatocytes, dilated blood sinusoids containing abnormal kupffer cells. Also, necrotic areas and some parts of cytoplasmic membrane are eroded.(Fig.B1)

Liver of rats were irradiated with of $\gamma$-irradiation and treated with acrylonitrile (group IV) revealed severe damage represented in fragmentation of nuclear chromatin, dissoluted mitochondria, thickened cell membrane, dilated bile canaliculus with complete loss of its microvilli. Also, increament of the number of lysosomes and lipid droplets were noticed (FigureB12).

The ultrastructure of rats liver treated with hesperidin (group V) showed nearly normal hepatocytes with normal mitochondria, rough endoplasmic reticulum and nuclear membrane with nearly normal arrangement of chromatin.(Fig. B13)

Liver of rats treated with hesperidin and irradiated with $\gamma$-radiation (group VI) revealed improvement in nuclear membrane. Oval shape nuclei, binucleated hepatocyte, restoration of cytoplasmic membrane. Regeneration in endoplasmic reticulum and mitochondria were detected. Also improvement of bile canaliculus and its microvilli However, some lipid droplets are still detected.(Fig. B14) 
In double treatment with acrylonitrile and hesperidin (group VII), liver ultra-sections showed ameliorated nuclear membrane, nearly normal- shaped rough endoplasmic reticulum and improvement of some mitochondria.However others are still deformed and necrotic areas still appeared.(Fig. B15)

Liver ultrasections of rats treated with acrylonitrile and hesperidin and exposed to $\gamma$ irradiation (group VIII) showed regeneration of some hepatocyte, binucleated hepatocyte and improvement of some mitochondria.However others were still damaged and electron dense.Meanwhile restorated rough endoplasmic reticulum and some parts of cell membrane showed improvement.Other parts are still eroded.(Fig. B16)

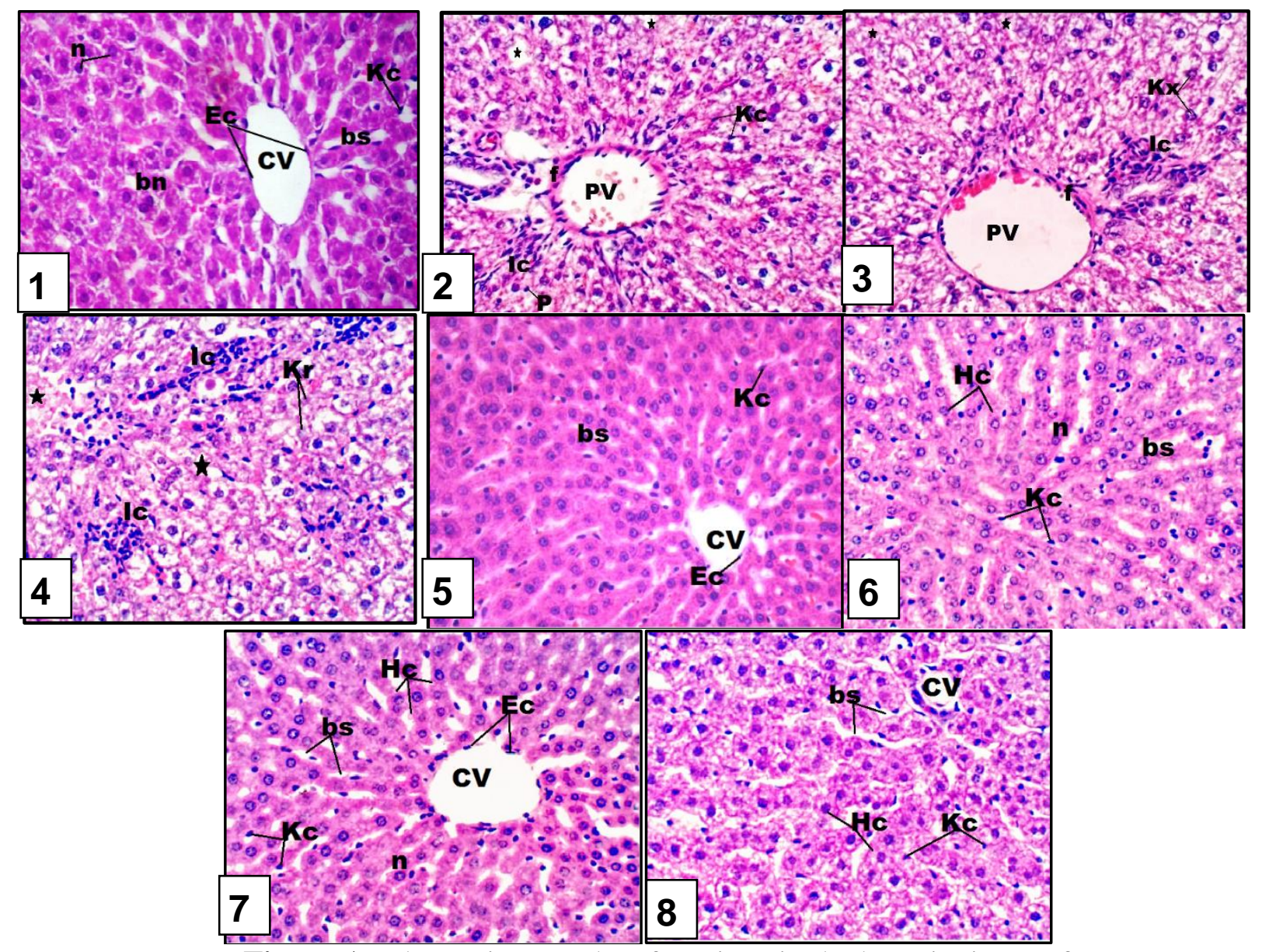

Figure A: Photomicrographs of sections in the hepatic tissue of rats $(\mathrm{H} \& \mathrm{E} \mathrm{X} 400)$.

(1) Control group: The cellular architecture of the liver is formed of cords composed of nucleated (n) or binucleated (bn) hepatocytes, one to two cell layers thick, separated by blood sinusoid (bs), the central vein (CV) and kupffer cells (Kc) were appeared.X400

(2) $\boldsymbol{\gamma}$-R group:Dilatation of portal vein surrounded by fibrous tissues, inflammatory infiltrative cells, patches of necrotic areas $(*)$ some pyknotic nuclei $(\mathrm{P})$ were shown.X400

(3) ACN treated group: Dilatedportal vein surrounded by fibrous tissue, also inflammatory infiltrative cells (Ic), active kupffer cells, karyorrhexis( $\mathrm{Kx})$ andkaryolysis(Kr) were shown.X400 (4) $\gamma-\mathbf{R}+$ ACN group: Liver photomicrograph shows necrotic regions $(*)$, karyolysis (Kr), inflammatory infiltrative cells (Ic).X400 
(5) Hes treated group: Liver photomicrographshows nearly normal hepatic lobule in which the hepatocytes were arranged in cords radiating from the central veins (CV) and central rounded nuclei, normal blood sinusoids (bs) and kupffer cells (kc) were shown.X400

(6) $\gamma$-R + Hes group:The liver tissue appeared withwell-developed hepatic cords( $\mathrm{Hc})$, kupffercells(kc) and blood sinusoid(bs), improved hepatocytes with rounded nuclei(n) were shown.X400

(7) CAN + Hes treated group:The liver tissue shows improvement in the structure of the central vein $(\mathrm{CV})$ lined with endothelial cells $(\mathrm{Ec})$, hepatic cords (Hc),blood sinusoid (bs) andkupffer cells $(\mathrm{kc}) \cdot \mathrm{X} 400$

(8) $\gamma$-R + CAN + Hes group:The liver tissue shows improvement in central vein (CV), hepatic cords $(\mathrm{Hc})$, blood sinusoid (bs) andkupffer cells $(\mathrm{kc})$. X400

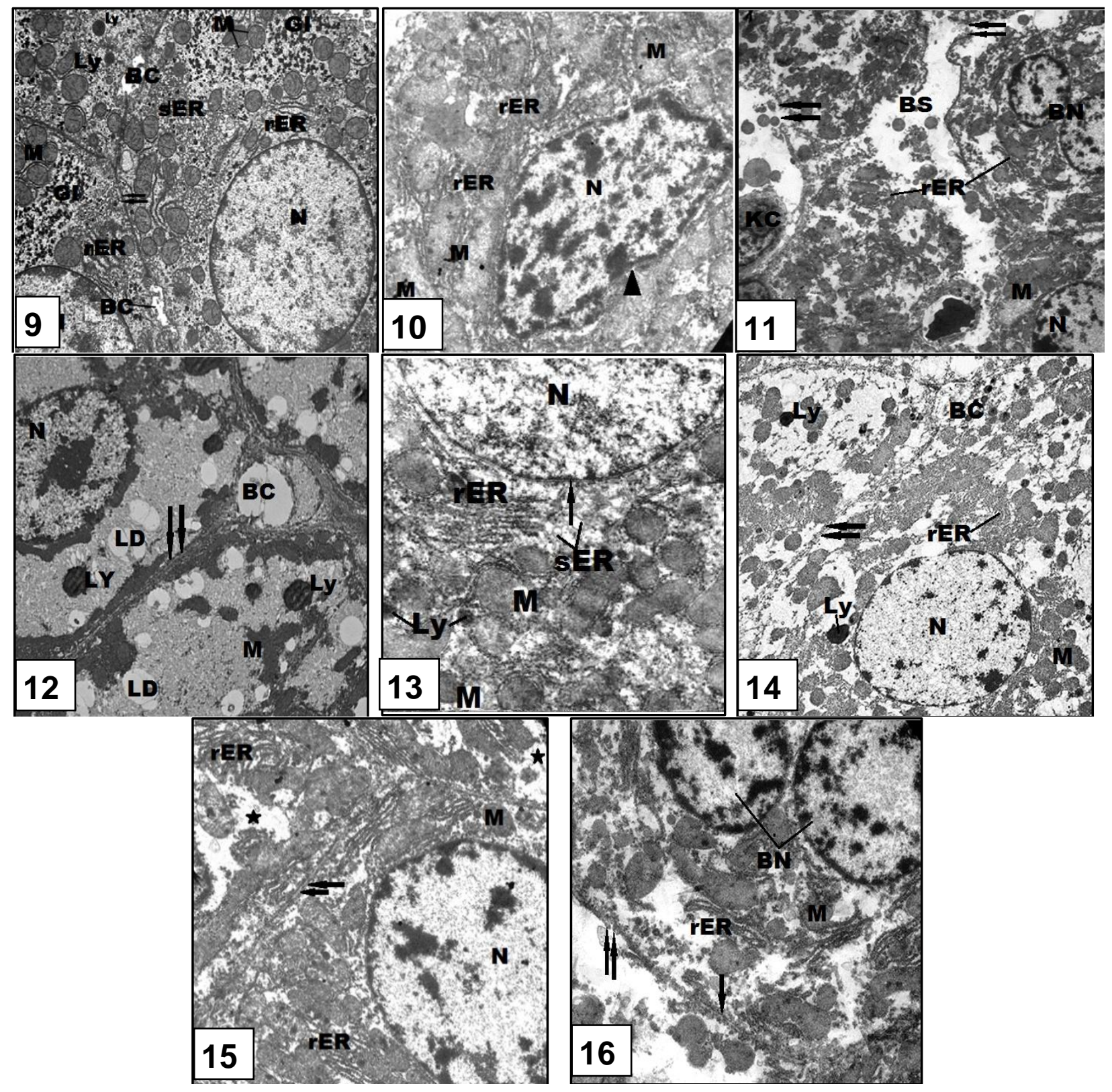


Figure B: Electron micrographs of sections in the hepatic tissue of rats.

(9) Control group: The liver tissueshows normal hepatocytes with normal nucleus (N), mitochondria $(\mathrm{M})$, rough(rER) and smooth endoplasmic reticulum (SER) and normal bile duct. The bile canaliculus (BC) and glycogen inclusions are evident. X2600

(10) $\gamma$-R group: The liver electron micrographshows wrinkled nuclear membrane with abnormal chromatin, swollen mitochondria (M) with deteriorated cristae. X2000.

(11) ACN treated group: The liver electron micrographshows binucleated hepatocyte(BN), dilated blood sinusoid containing abnormal Kupffer cell (KC), deformed mitochondria (M)disrupted rough endoplasmic reticulum (rER) and rupture of cell membrane (double arrows).X660. (12) $\boldsymbol{\gamma}$-R+ ACN group: The liver electron micrographshows, cytoplasm containing deformed and electron dense mitochondria (M) and increased lipid droplets (LD), lysosomes, thickened cellmembrane (double arrows) and dilated bile canaliculus (BC) with complete loss of its microvilli. X1300.

(13) Hes treated group:The liver electron micrograph shows nearly normal hepatocyte and mitochondria $(\mathrm{M})$, rough edoplasmic reticulum (rER) and nuclear envelope.

(14) $\boldsymbol{\gamma}$-R + Hes group:The liver electron micrograph shows improvement in nuclear membrane, regeneration in endoplasmic reticulum (rER) and nearly normal mitochondria (M), lysosomes(Ly), intact cell membrane (double arrows), bile canaliculus (BC) with partial loss of microvilli. X1300

(15) CAN + Hes treated group:The liver electron micrographshows ameliorated nuclear membrane, nearly normal- shaped rough endoplasmic reticulum (rER), improvement of some mitochondria (M) others are still deformed, intact cell membrane(double arrows) and some necrotic $\operatorname{areas}(*) . \mathrm{X} 2000$.

(16) $\boldsymbol{\gamma}$-R + CAN + Hes group:The liver electron micrographshows binucleated (BN) hepatocyte, improvement of some mitochondria (M) however others are still damaged and electron dense.Restorated rough endoplasmic reticulum (rER) and improvement of some parts of cell membrane (arrows) however other parts are still eroded (double arrows). X1600.

\subsection{Disscusion}

Gammaradiation is an electromagnetic wave that is characterized by its short wavelength and high-energy. Radiation has the ability to break chemical bonds, cause ionization and produce free radicals that induce biological damage (Hall, 2000). In the present study liver tissues of rats exposed to $\gamma$-radiation showed hepatic lesions that included cell necrosis, congested central veins, dilated blood sinusoids andactive kupffer cells and pyknotic, karyolysed and binucleated liver cells also leucocytic cellular infiltration were detected.

Similar results were documented by many authors on different experimental animals exposed to $\gamma$-radiation Pradeep et al. (2008) and Qi et al (2011). Theyattributed this damage to the hazard effects of ionizing radiation which acts directly on nucleic acids, proteins and enzymes, causing ionization and breakage of chemical bonds leading to disruption of the molecular structure and finally to cell damage.Also Nassaret al. (2008) and Eid et al. (2015) demonstrated that the liver tissue of $\gamma$-irradiated (5Gy) rats resulted in many pathological signs such as hydropic degeneration, cytoplasmic vacuolation, nuclear pyknosis and karyolysis, nucleoli disappearance, necrosis, and leucocytic infiltration.Moreover, Radyet al.(2008) attributed the induction of liver cell necrosis by $\gamma$-irradiation to the progressive degenerative 
action of intercellular enzymes of the injured cells or to a metabolic disturbance and inhibition of DNA and protein synthesis needed for the growth and maturation of the cells.

On the other hand, Yuanyuanet al. (2009) reported that radiation exposure stimulates fibroblast proliferation and enhance inflammatory response; these results were attributed to the role of radiation exposure in induction of growth factors and cytokines production, such as tumour necrosis factor, and interleukins. Also Lee et al. (2008); Kotzampassiet al. (2009)attributed the histological abnormalities and liver injury induced by gamma- radiation to its role in lipid peroxidation, where free radicals, generated by radiation- attack biomolecules such as the fatty acid component of membrane lipids and DNA, leading to lipid peroxidation.

In this study, applying electron microscopy to examine liver sections of albino rats exposed to gamma radiation revealed severe deteriorative changes, which appeared as nuclear lesions, as well as dilated plasmic membrane, swollen fused mitochondria with ill-differentiated cristae and fragmentation of the rough endoplasmic reticulum. These findings agree with those obtained by Abu-Nour (2008). who atributed that the mitochondrial swelling and destruction of their cristae are due to the influx of water into the inner and outer mitochondrial chambers, which is accompanied by separation of the inner and outer mitochondrial membranes and induces the failure of the mitochondrial activity in the damaged cells.

Moreover, some cytoplasmic vacuolation, as well as vesiculation and fragmentation of the rough endoplasmic reticulum after the exposure of accumulated dose of gamma radiation were also confirmedby Radyet al. (2008). They reported that cytoplasmic vacuolation as a result of irradiation to a progressiveischemia or hypoxia and partly to either hydrophopicdegeneration caused by more emission of water into the metabolically disturbed cells or fatty degeneration caused by lipid abundance in such cells. Also they attributed the fragmentation or vesiculation of endoplasmic reticulum to the ingression of water and solutes into the cell which was referred to dysfunction of the cell membrane permeability.

Acrylonitrile (ACN), an organic nitrile, is widely used in the manufacturing of fibers, plastics and pharmaceuticals.Its exposure shows characteristics of cyanide poisoning (Haber and Patterson, 2005). Our present study revealed different histopathological alterations after the administration of acrylonitrile such as dilatation of the portal veins which were surrounded by fibrous tissues, inflammatory cells, and dilatation in blood sinusoids, invasion of kupffer cells, haemorrhagic areas, swollen hepatocytes and obvious necrotic regions. Also, the nuclei displayed changes karyorrhexis, pyknosis and karyolysis. The present results are in agreement withBrodkin et al. (2001), Cave et al. (2011)and Cheryl et al. (2012) whomentioned that cytotoxicity induced by acrylonitrile may potentially be involved in apoptosis and necrosis, which resulted in DNA fragmentation.Generally, the oxidative stress induced by acrylonitrile is attributed to the conjugation with reduced glutathione $\mathrm{GSH}$; this process results in a rapid depletion of cellular antioxidant contents or to liberation of cyanide from acrylonitrile metabolism. Cyanide is a potent generator of ROS production via inhibition of the mitochondrial respiratory chain as well as an inhibiting the activities of other antioxidant enzymes (Rongzhu $\boldsymbol{e t}$ al. 2009).

By applying electron microscopy severe deteriorative changes are detected as swollen mitochondria with ill-defined cristae, fragmentation of rER, and increased number of lysosomes. Also, electron dense nuclear chromatin and irregularity of the nuclear envelope were seen. Ourresults are consistent with those of Abd-El Azeimet al. (2012) whoreported that toxicity 
induced by ACN showeddegenerative changes in Leydig cells exhibited asill-defined cell membrane,irregular nuclear envelope, mitochondrial disruption with loss of cristae, and a decrease in amount of the smooth endoplasmic reticulum. They also attributed these alterations to the liberation of reactive oxygen species ROS that exerts a potent damaging effect on the cells especially phospholipids of biological membranes. Also our results are in accordance with Ahmed (2015) who recorded that the increase of the number of lysosomes in acrylamide treated group. He attributed the lysosomal changes to its role in the digestion of damaged portions of the hepatocyte organelles.

Hesperidin is the predominant flavonoid in citrus fruits, it has free radical scavenging properties and antioxidant nature that preserved the integrity of tissue (Kalpanaet al., 2011).Our histological and ultrastructural results declared noticeable improvement of the hepatic tissue treated with hesperidin after theexposure to $\gamma$-radiation or/and acrylonitrile. These ameliorative effects may be attributed to the role of hesperidin in the induction of the antioxidant enzymesglutathione peroxidase GSH-Px and glutathione reductase GR, which are two major enzymes involved in maintaining redox balance in hepatocytes (Sen et al.,1994). The results confirmed studies performed by Miyake et al. (1998) and Viswanatha et al. (2012) who proved that oxidative stress-induced damage to mitochondria, where hesperidin pretreatment was found to significantly restores the mitochondrial enzyme activity and improve antioxidant levels in rat liver.

\section{Conclusion}

Restricted requirements are needed for reducing acrylonitrile an organic nitrile, which is widely used in the manufacturing of fibers, plastics and pharmaceuticals, and to attenuate the hazard effects of gamma radiation. Daily supplementation of hesperidin a flavanone-type flavonoid, which is found abundant in citrus fruit is necessary for reducing the harmful effects.

\section{References}

Abd-El Azeim B. H.;Abd-Ellah H. F. and Mohamed N. E. Prophylactic role of $\beta$-carotene against acrylonitrile-induced testicular toxicity in rats: Physiological and Microscopical studies. The Journal of Basic \& Applied Zoology 65, 257-266(2012).

Abo-Salem O. M.; Mohamed F.;Abd-Ellah and Mabrouk M. Ghonaim.Hepatoprotective Activity of Quercetin against Acrylonitrile-Induced Hepatotoxicity in Rats. J Biochem Molecular Toxicology 25:386-392(2011).

Abu-Nour, S. M.; Rady, M. I. and Khalil, I. M. Protective effect of $\beta$-carotene on gamma radiation induced renal histological and ultrastructural changes in male albino rats. Al-Azhar Bull. Sci., 19(1):27-44(2008).

Ahmed A. S. S. Possible Protective Effect of Certain Flavonoid against Flutamide-Induced Hepatotoxicity in Adult Male Rats. Ph.DThesisFaculty of Women for Arts, Science and Education-Ain Shams University(2015). 
Benkovic, V.;Knezevic, A. H.;Dikic, D.;Lisicic, D.;Orsolic, N.; Basic, I.;Kosalec, I., andKopjar, N. Radioprotective effects of propolis and quercetin in gamma-irradiated mice evaluated by the alkaline comet assay.Phytomedicine, 15, 851-858(2008).

Brodkin C.A.; Moon J.D.; Camp J.; Echeverria D.;Redlich C.A.;Willson R.A. and Checkoway H. Serum hepatic biochemical activity in two populations of workers exposed to styrene.Occupational and environmental medicine. 58:95-102(2001).

Cave M.; Falkner K.C.; Henry L.; Costello B.; Gregory B. and McClain C.J. Serum cytokeratin 18 and cytokine elevations suggest a high prevalence of occupational liver disease in highly exposed elastomer/polymer workers. J Occup Environ Med. 53(10): 11281133(2011).

Cheryl A. H.;Rajendra S. C.; Leslie R.; Michael S. and Kristine L. W. Genotoxicity of Styrene-Acrylonitrile Trimer in Brain, Liver, and Blood Cells of Weanling F344 Rats. Environ Mol Mutagen. 53(3): 227-238(2012).

Eid F.A.; El-Gendy A.M.;Zahkouk S.A.; El-Tahway N.A. and El-Shamy S.A. Ameliorative Effect of Two Antioxidants on The Liver of Male Albino Rats Exposed to Electromagnetic Field. The Egyptian Journal of Hospital Medicine 58: 74-93(2015).

El-Sayed, S. M.; Abo-Salem, O. M.;Abd-Ellah, M. F. and Abd-Alla, G. M. Hesperidin, an antioxidant flavonoid, prevents acrylonitrile-induced oxidative stress in rat brain.J. Biochem. Mol. Toxicol. 22, 268-273(2008).

Haber, L.T. and Patterson, J., Report of an independent peer review of an acrylonitrile risk assessment. Hum. Exp. Toxicol. 24 (10), 487-527(2005).

Hall, E. J. Radiation, the two-edged sword: cancer risks at high and low doses. Cancer Journal, 6: 343-350(2000).

Harris's, H. F. HistochemicalTechn., By Methuen and Co. Ltd. (1900).

Kalpana K. B.;Devipriya N.; Srinivasan M.;Vishwanathan P.;Thayalan K. and Menon V. P. Evaluating the radioprotective effect of hesperidin in the liver of Swiss albino mice. European Journal of Pharmacology 658: 206-212(2011).

Kamat, J.P.;Boloor, K.K.;Devasagayam, T.P.A. andVenkatachalam, S.R.Antioxidant properties of Asparagussracemous against damage induced by gamma radiation in rat liver mitochondria.J. Ethnopharmacol. 71, 425-435(2000).

Kanimozhi, G.; Prasad, N. R.; Ramachandran, S. andPugalendi, K. V.Umbelliferone modulates gamma-radiation inducedreactive oxygen species generation and subsequent oxidative damage in human blood lymphocytes. European Journal of Pharmacology, 672, 2029(2011).

Kátia A. S.Sterilization by Gamma Irradiation, In Gamma Radiation, Prof. FerizAdrovic (Ed.),ISBN: 978-953-51-0316-5, pp. 171- 206(2012).

Kotzampassi K.;Tzitzikas Y.;Papavramidis T.S.;Kolettas A.;Vrettou E.;Spiliadi Ch.;Paramythiotis D.; Metaxas G. and Eleftheriadis E. N-3 fatty acids ameliorate radiation-induced liver injury in the rat. Annals of Gastroenterology 22(2):106-111(2009). 
Kuntic V.;Brboric J.;Antunovic I. H. and Markovic S. U. Evaluating the bioactive effects of flavonoid hesperidin - A new literature data survey.Vojnosanit Pregl., 71(1): 60-65(2014).

Lee H.S.; Jung K.H., Hong S.W.; Park I.S.; Lee C.; Han H.K.; Lee D.H. and Hong S.S. Morin protects acute liver damage by carbon tetrachloride (CCL4) in rats. Arch. Pharmacol. Res., 31 (9): 1160-1165(2008).

Lin, Q.; Chun-Yu, L.; Wen-Qian, W.; Zhen-Lun, G. and Ci-Yi, G.Protective effect of flavonoids from Astragaluscomplanatus on radiation induced damages in mice. Fitoterapia; 82: 383-392(2011).

Miyake, Y.; Yamamoto, K.;Tsujihara, N. andOsawa, T. Protective effects of lemon flavonoids on oxidative stress in diabetic rats. Lipids 33:689-695(1998).

Mothersill, C. and Seymour, C.Radiation-induced bystander effects: are they good, bad or both? Medicine. Med ConflSurviv 21:101-10(2005).

Nassar, S. A.;Ghonemy, O. I.;El-Serafy, S.;Roushdy, H. M. and AbdEl-Hady, A. M. Silymarin protects the histological pattern of rat liver against radiation toxicity. EJHM; 32: 277- 288(2008).

Paul, P.;Unnikrishnan, M. K. andNagappa, A. N. Phytochemicals as radioprotective agents a review.Indian Journal of Natural Products and Resources; 2: 137-150(2011).

Pradeep, K.; Park, S. H. andKo, K. C. Hesperidin a flavanoglycone protects against $\gamma$ irradiation induced hepatocellular damage and oxidative stress in Sprague-Dawley rats.European Journal of Pharmacology; 587:273-280(2008).

Qi, L.; Liu, C.Y.; Wu, W.Q.;Gu, Z.L. andGuo, C.Y. Protective effect of flavonoids from Astragaluscomplanatus on radiation induced damages in mice. Fitoterapia; 82:383-392(2011).

Rady, M. I.; Abu-Nour, S. M. and Khalil, I. M. Effect of gamma radiation on the albino rat's liver and possible protective role of $\beta$-carotene on the histological ultrastructural changes. Egypt. Rad. Sci. Applic; 21(2):373-388(2008).

Ran, Y.; Wang, R.; Gao, Q.;Jia, Q.; Hasan, M.; Awan, M.U.; Tang, B.; Zhou, R.; Dong, Y.; Wang, X.; Li, Q.; Ma, H.; Deng, Y. and Qing, H. Dragon's blood and its extracts attenuate radiation-induced oxidative stress in mice. Journal of Radiation Research; 55: 699706(2014).

Rongzhu, L.; Wang, S.; Xing, G.; Ren, C.; Han, F.; Chen, S.; Zhang, Z.; Zhu, Q. and Michael, A. Effects of acrylonitrile on antioxidant status of different brain regions in rats. Neurochemistry International; 55:552-557(2009).

Sen, C.K.; Packer, L. and Hanninen, O. Physiological antioxidants. In: Exercise and oxygen toxicity. Amsterdam. The Netherlands: Elsevier Science; 89-126 (1994).

Seyed, J.; Hosseini,M.; Hassan, T.;Gholamreza, P.;Aligholi, S. and Abbas, S.Radioprotective Effects of Citrus Extract Against gamma-Irradiation in Mouse BoneMarrow Cells. J. Radiat. Res; 44: 237-241(2003).

Tirkey, N.;Pilkhwal, S.;Kuhad, A. and Chopra, K.Hesperidin, a citrus bioflavonoid, decreases the oxidative stress produced by carbon tetrachloride in rat liver and kidney. BMC Pharmacol; 31(5):2(2005). 
Tommasini, S.;Calabro, M.L.;Stancanelli, R.; Donato, P.; Costa, C.; Catania, S.;Villari, V.;Ficarra, P. andFicarra, R. The inclusion complexes of hesperetin and its 7rhamnoglucoside with (2-hydroxypropyl)- $\beta$-cyclodextrin.J. Pharm. Biomed. Anal; 39: 572580(2005).

Viswanatha, G. L.;Shylaja, H.;SandeepRao, K. S.;SanthoshKumar, V. R. and Jagadeesh, M. Hesperidin Ameliorates Immobilization-Stress-Induced Behavioral and Biochemical Alterations and Mitochondrial Dysfunction in Mice by Modulating Nitrergic Pathway. ISRN PharmacologyVolume 2012, Article ID 479570, 8 pages doi:10.5402/2012/479570(2012).

Weakley, B. S. A beginner's Handbook in biological transmission electron microscopy, $2^{\text {nd }}$ ed., London, Churchill Livingstone(1981). 
الملخص باللغة العربية

التأثير المخفف لمضاد الأكسدة الفلافونويد على التركيب الهيستولوجي والتركيب الدقيق لكبد الجرذان المهقاء المعاملة بالأشعاع و/أو بمركب أكريلونيتريل.

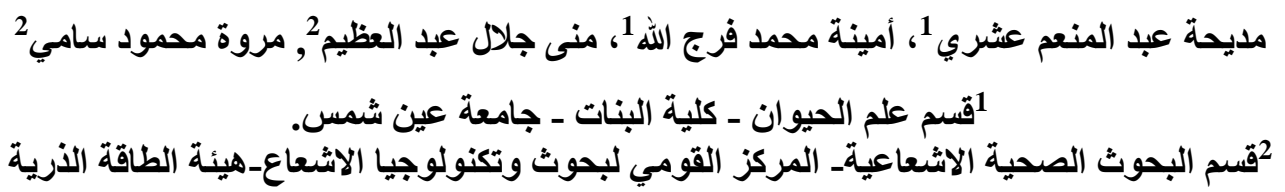

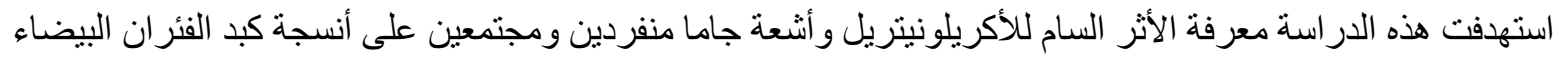

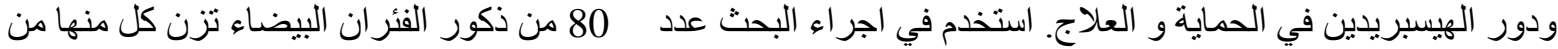

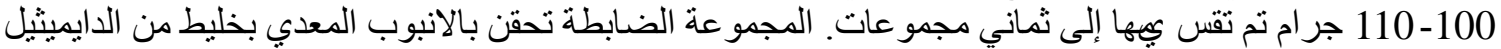

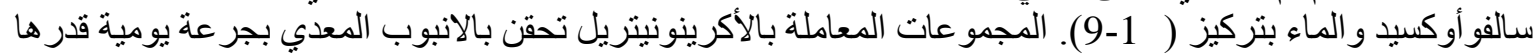

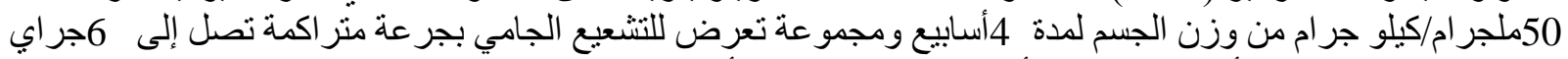

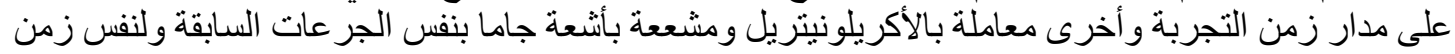

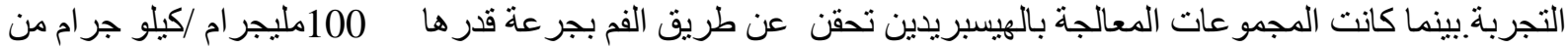

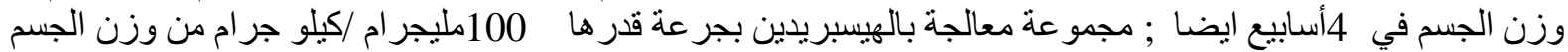

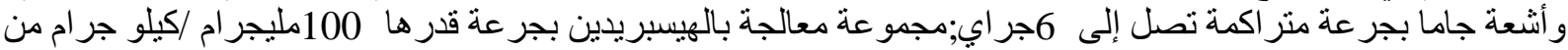

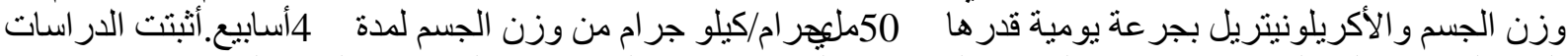

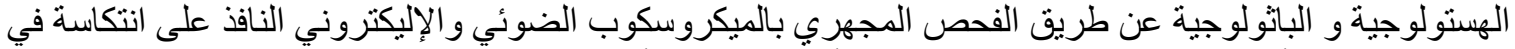

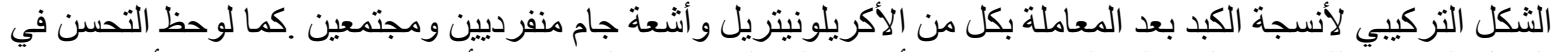

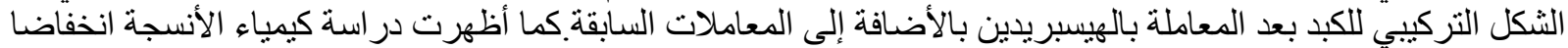

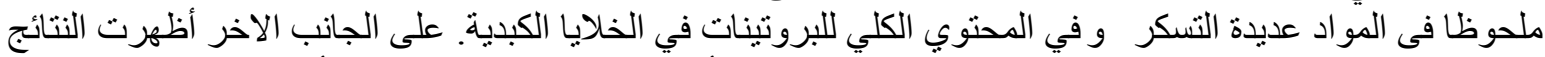

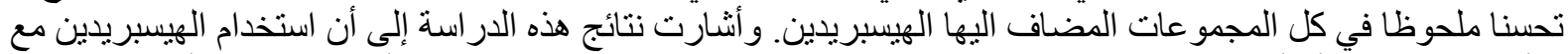

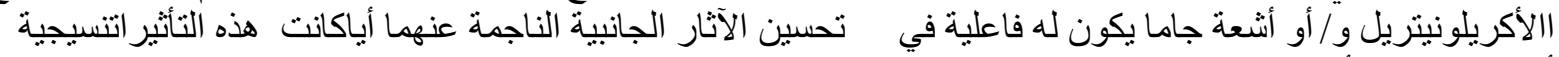
أوتركيبية دقيقة أو هيستوكيميائية. 